\title{
Degenerative Lumbar Disc Disease: A Questionnaire Survey of Management Practice in India and Review of Literature
}

\author{
Vinu V. Gopal ${ }^{1}$ \\ ${ }^{1}$ Department of Neurosurgery, Medical College, "Gowreesapattom," \\ Kottayam, Kerala, India
}

J Neurosci Rural Pract:2021;12:159-164
Address for correspondence Vinu V. Gopal, MS, MCh, Mphil, Department of Neurosurgery, Government Medical college, Kottayam, Kerala 686008, India (e-mail: vinoogopa@gmail.com).

\begin{abstract}
Keywords

- lumbar disc

- management

- survey

Objective To identify the current management modalities practiced by neurosurgeons in India for degenerative lumbar disc disease.

Materials and Methods Survey questionnaires were prepared in Google forms. It covered the following aspects of managing the lumbar disc pathology: (1) Demographic, institutional details, experience of surgeons, (2)choice of surgical procedures, (3) use of endoscopy and minimally invasive techniques, and (4) pre- and postoperative care. Responses obtained were entered in SPSS datasheet and analyzed.

Results Of the 300 surveys sent, 80 were returned and response rate was $26.6 \%$. But four surveys were highly incomplete and were discarded from the analysis. So, the study content is from the analysis of practices of 76 spinal surgeons working in different parts of the country. Majority of the spine surgeons $(n=70)$ were neurosurgeons, while 6 were orthopaedic surgeons. Fifty-four were from urban area, 12 from semiurban area, and 10 from rural area. Forty-seven spine surgeons practiced in a teaching hospital. Total $73.6 \%$ of spine surgeons opted initial medical management. Sixty-three percent preferred microlumbar discectomy (MLD) and only eight neurosurgeons preferred minimally invasive techniques. None of the respondents used in situ fusion. Fifty-three percent of spine surgeons preferred early mobilization (first postoperative day). Fifty-nine percent preferred to follow-up patients clinically and opted for magnetic resonance imaging only when recurrence or infection was suspected. The institutional nature (government teaching, government nonteaching, private teaching, and private nonteaching) and location of the hospital (urban/semiurban/rural) were found to be influencing the preferred surgical technique, trial of medical management, or postoperative care and complications. Considerable practice variations exist for medical and perioperative management.

Conclusion The preferred treatment of choice of majority was MLD, although laminectomy and discectomy were still used by many. Consensus lacks in the operative, perioperative, and postoperative management of degenerative disc disease. Present survey points toward the importance of making management guidelines for this common spinal surgical entity.
\end{abstract}

DOI https://doi.org/

10.1055/s-0040-1722103

ISSN 0976-3147. (c) 2021. Association for Helping Neurosurgical Sick People.

This is an open access article published by Thieme under the terms of the Creative Commons Attribution-NonDerivative-NonCommercial-License, permitting copying and reproduction so long as the original work is given appropriate credit. Contents may not be used for commercial purposes, or adapted, remixed, transformed or built upon. (https://creativecommons.org/licenses/by-nc-nd/4.0/). Thieme Medical and Scientific Publishers Pvt. Ltd. A-12, 2nd Floor, Sector 2, Noida-201301 UP, India 


\section{Introduction}

Herniated lumbar disc is a very common condition encountered in day-to-day neurosurgical practice. ${ }^{1}$ There is insufficient evidence for the use of conservative medical management in lumbar disc pathology. The use of open surgery, its timing, comparison to conservative treatment is still controversial. The usual care is elusive and unexplained by level 1 evidence and randomized controlled trials. ${ }^{1-3}$ General practice variations do exist based on expertise of the surgeon, rural/urban status, and availability of modern facilities. These variations also may have impact and additional influence on disease recurrence.

Our survey is an analytical attempt to document the various practice modalities advocated by spinal surgeons across the country. The results of our study will benefit medical fraternity by providing data regarding current practice trends in lumbar disc disease management. This nationwide survey on degenerative lumbar disc disease gives useful insight to the management practices in India for this common spinal surgical entity.

\section{Materials and Methods}

Survey questionnaire was prepared and entered in Google forms and send by e-mail to spine surgeons. It covered the following aspects of managing the lumbar disc pathology: (1) demographic, institutional details, experience of surgeons, (2) choice of surgical procedures, (3) use of endoscopy and minimally invasive techniques, and (4) pre- and postoperative care.

\section{Survey}

Questionnaire was prepared based on previous studies. ${ }^{1,2}$ As a pilot study, survey questionnaire was initially sent to four senior neurosurgeons working in various parts of the country. Upon expert review panel corrections were made as per suggestions which we felt improved the readability and validity of the questionnaire. Final form was sent to 300 spine surgeons by e-mail. Majority of questions could be answered by selecting from the multiple choices given in the e-mail or in the web interphase and few required the participant to write a short sentence. At 4 and 6 weeks, e-mail was again sent for nonresponders. The questionnaire used is given in - Fig. 1.

We closed the study at 12 weeks. Data recorded in Google spreadsheet was entered in SPSS version 16 (SPSS Inc., Chicago, Illinois, United States). Most of the statistics done were descriptive in nature. Differences in response between categories were assessed by chi-square test and $p$-value of less than 0.05 was taken as significant.

\section{Results}

Of the 300 surveys sent, 80 were returned and response rate was $26.6 \%$. But four surveys were highly incomplete and were discarded from the analysis. So, the study content is from the analysis of practices of 76 neurosurgeons working in different parts of the country.

\section{Demography}

Majority of the spine surgeons $(n=70)$ were neurosurgeons, while 6 were orthopaedic surgeons. Most spine surgeons were from urban area, $n=54(71 \%)$ and 12 were from semiurban area. Only 10 spine surgeons were from rural area. Forty-seven responders were practicing in teaching hospital of which 35 worked in government hospitals and 12 in private teaching hospital. Twenty-nine were practicing in private nonteaching hospitals. Hospital location and nature of institution of the survey participants are shown in - Fig. 2.

Majority had an annual case load of $>200$ cases. Total number of cases operated by respondents annually is shown in - Fig. 3.

More number of cases were done in government teaching hospital and the difference was statistically significant $(p$-value $=0.023)$.

\section{Trial of Medical Management}

Our survey showed that $73.6 \%(n=56)$ preferred an initial conservative management in symptomatic lumbar disc disease. Twenty-two spine surgeons (39\%) used analgesics along with

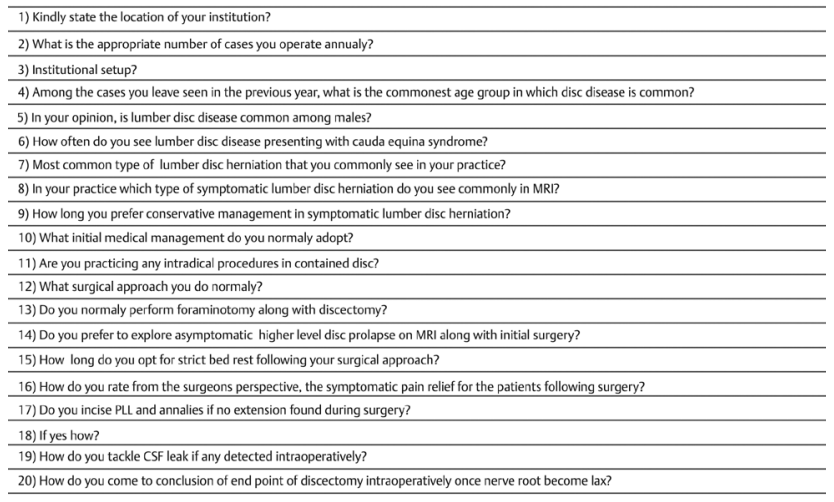

Fig. 1 Questionnaire.

LOCATION OF INSTITUTION

u URBAN a SEMIURBAN

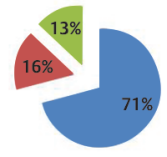

\begin{tabular}{|l|l|l|l|}
\hline Question & $\begin{array}{l}\text { Total number of } \\
\text { responses }\end{array}$ & Respondent subgroups & $N(\%)$ in each subgroups \\
\hline \multirow{2}{*}{ location of hospital } & 76 & Rural & $10(13 \%)$ \\
& & Semirural & $12(16 \%)$ \\
\cline { 3 - 3 } & & Urban & $54(71 \%)$ \\
\hline \multirow{2}{*}{ Hospital setting } & 76 & $\begin{array}{l}\text { Covt and private } \\
\text { (Teaching) }\end{array}$ & $47(61.8 \%)$ \\
\cline { 3 - 3 } & & Non teaching hospital & $29(38.1 \%)$ \\
\hline
\end{tabular}

Fig. 2 Hospital location and nature of institution of survey participants. 
bed rest as the first-line conservative management. Trial duration of medical management chosen by majority was 4 weeks.

Fifty-six percentage $(n=31)$ believe that life style modification along with avoidance of substance abuse reduced the incidence of lumbar disc disease. The options of medical management chosen by the respondents are given in $\boldsymbol{- F i g} . \mathbf{4}$.

Of the 56 spine surgeons who advocated medical treatment as the initial management, 7 opted steroids; 6 used traction as the initial medical management. Twenty-two advocated strict bed rest and analgesics and twenty-one opted membrane stabilizers along with analgesics as initial medical management.

\section{Surgical Procedure of Choice}

The extent of bone removal (laminectomy/hemilaminectomy, flavotomy/minimally invasive spine surgery [MISS]) varied from one surgeon to another. Our survey showed that 48 surgeons (63\%) preferred microlumbar discectomy (MLD), 20 (26\%) opted laminectomy and discectomy, and 8 preferred minimally invasive methods. Percutaneous discectomy $(n=9,52.9 \%)$ was the preferred intradiscal procedure. Sixtyseven percent $(n=48)$ preferred to do foraminotomy to release nerve root along with routine discectomy. Preferred modalities of surgery and intradiscal therapy chosen by respondents are shown in $\boldsymbol{- F i g .} \mathbf{5}$.

During surgery, if no disc extrusion was found, majority $(77.8 \%, n=56)$ incise the posterior longitudinal ligament (PLL) to retrieve the disc. If cerebrospinal fluid (CSF) leak was detected intraoperatively, 32 (42\%) preferred to widen the defect and resuture and 3.3\% preferred to give acetazolamide postoperatively. Half of the respondents who opted MLD decided on the end point of discectomy by microscopic intradiscal visualization. At the end of laminectomy, 19 (31\%) surgeons placed a Gelfoam over the dura. None of the respondent used in situ fusion procedure. In asymptomatic higher level disc prolapse which was evident on magnetic resonance imaging (MRI) preoperatively, majority $(94.4 \%, n=34)$ preferred not to explore along with initial surgery.

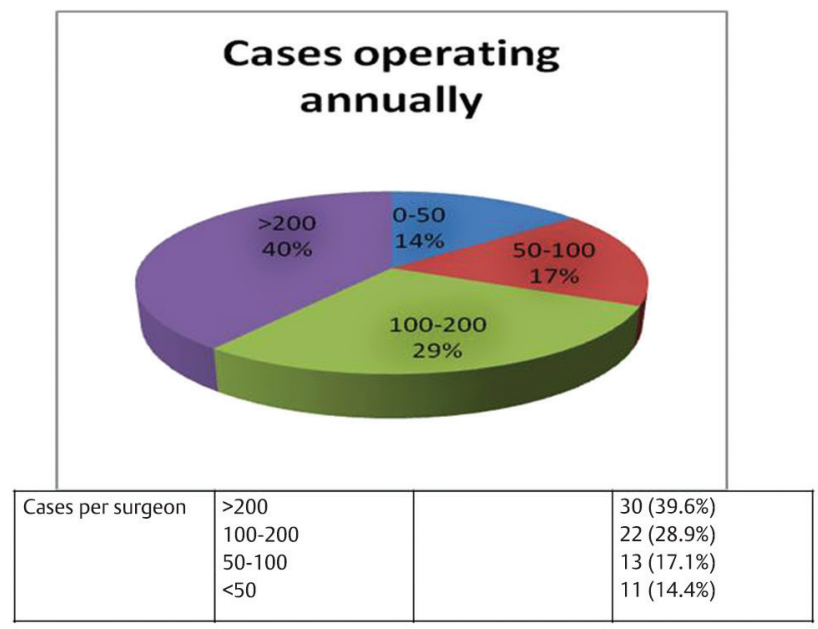

Fig. 3 Annual number of cases operated by respondents.
Fifty-three per cent of spine surgeons preferred early mobilization on first postoperative day. Symptomatic pain relief following surgery was given a mean score of 8 by majority $(n=26,36 \%)$ as measured on a continuous scale from 1 to 10. This observation is shown in - Fig. 6 .

\section{Follow-up Evaluation}

Majority of the neurosurgeons $(n=36,59 \%)$ preferred to follow-up patients clinically and opted for MRI when

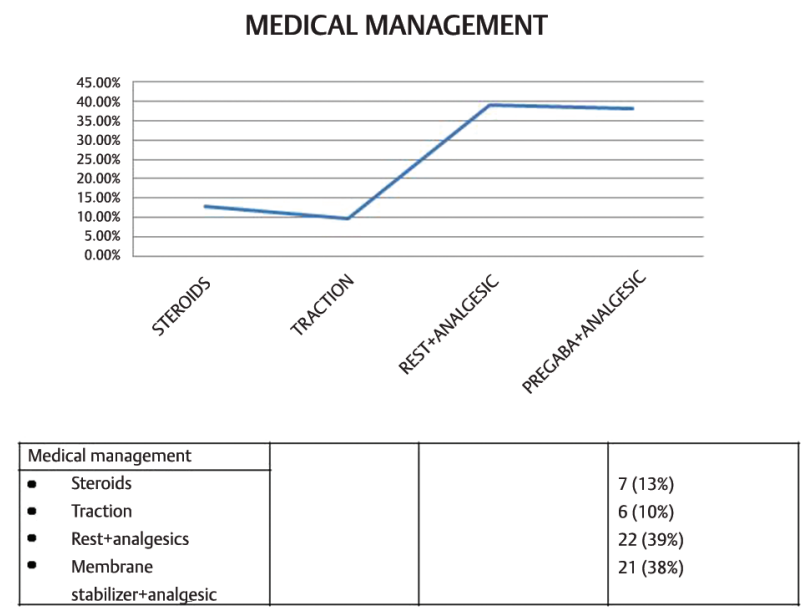

Fig. 4 The options of medical management chosen by the respondents.

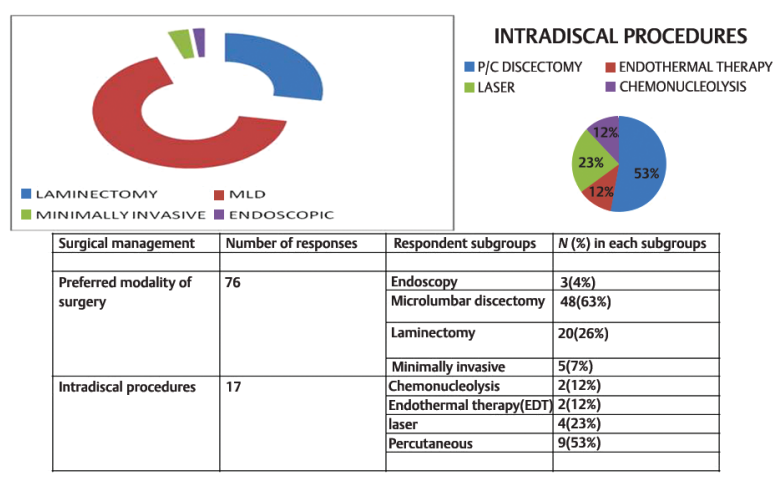

Fig. 5 Surgical preferences among respondents.

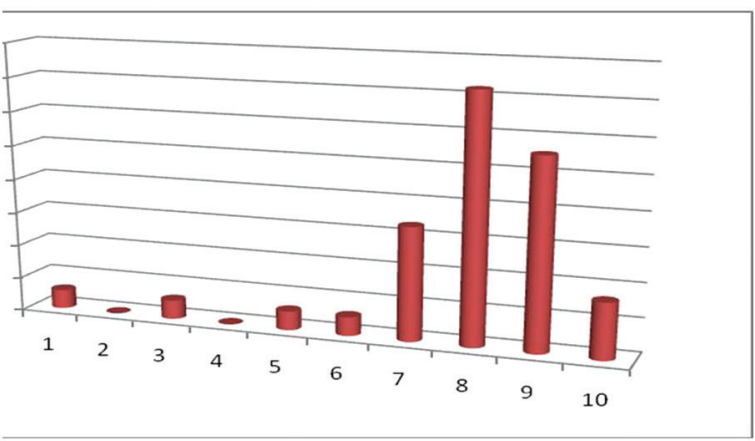

Fig. 6 Patient satisfaction measured on visual analog scale by individual respondents. 
recurrence is suspected clinically or when there is clinical evidence of postoperative discitis.

\section{Discussion}

Lumbar disc herniation is a common spinal condition that frequently affects the productive age group of our population. ${ }^{1}$ Neurosurgical intervention proved to provide the most efficient therapy for symptomatic lumbar disc disease. However, surgical treatment modalities vary from center to center and even among the surgeons in the same center. Class 2 evidence to accurately predict the surgical outcome is lacking in the literature. ${ }^{2}$ Apart from operating surgeon, institutional preferences also govern the treatment decisions. Lack of consensus also exists in optimal preoperative and postoperative care.

Lack of consensus also extends to optimal pre- and postoperative care and adjuvant therapy. We have conducted this survey to evaluate the management practices in India and to compare it to the available best practice recommendations as of today. Data from this survey is expected to show light into the existing practices against its actual role and may help in making future guidelines. The need for guidelines all the more becomes significant when a steady increase in incidence of degenerative disc disease is expected in India due to rise in life expectancy, new generation life styles.

\section{Conservative Medical Management}

Role of initial medical management such as use of nonsteroidal anti-inflammatory drugs, steroids, physical therapy techniques such as mild stretching and traction, ${ }^{4}$ ultrasound therapy, thermal therapy, and electrical stimulation lack level 1 evidence as management recommendation for and against their use. ${ }^{5,6}$ Buttermann ${ }^{7}$ and Saal and Saal ${ }^{8}$ conducted a prospective randomized study on the use of epidural steroids in management of lumbar disc pathology. The response to epidural injections is also variable and many authorities believe the injections are only of short-term value.

Present survey showed that 56 neurosurgeons opted for initial medical management in symptomatic patients. If there was no symptomatic relief after 6 weeks, 97\% of those who preferred initial conservative management opted surgery later on.

\section{Surgical Management}

Lumbar discectomy has shown a success rate of between 60 and $90 \%$ in failed conservative and symptomatic cases. ${ }^{9}$ Anderson et $\mathrm{al}^{3}$ and Atlas et $\mathrm{al}^{9}$ prospectively studied patient outcome and concluded that among those who have failed 6 weeks of conservative management, surgery is the best modality of treatment. ${ }^{3,9} \mathrm{~A} 2$-year results of a randomized controlled trial by Peul et $\mathrm{al}^{10}$ concluded the effectiveness of early surgical intervention. Spine Patient Outcomes Research Trial, a randomized trial by Weinstein et $\mathrm{al}^{2}$ also concluded initial effectiveness of surgical intervention. ${ }^{7,8}$ In our survey, $97 \%$ of those who preferred initial conservative management also opted surgery which is almost similar to that in the literature.

Preoperative optimization in the form of weight reduction and abstinence from smoking was found to have beneficial effect on patient outcome. ${ }^{7}$ Our survey showed that Indian neurosurgeons are aware and keen on educating patients regarding these preoperative optimization techniques.

The extent of bone removal (laminectomy/ hemilaminectomy/flavotomy/MISS) varied from one surgeon to another. ${ }^{11}$ In our study, majority, $n=48(63.1 \%)$ preferred MLD, and 26.3\% ( $n=20$ ) of neurosurgeons preferred to do laminectomy and discectomy for lumbar disc herniation. Eight neurosurgeons preferred endoscopic discectomy. Percutaneous discectomy $(n=9,53 \%)$ was the preferred intradiscal procedure. These data clearly show the management dilemma among surgeons and highlight the importance of a clear guideline for lumbar disc disease management.

\section{Open Laminectomy and Discectomy}

This is the commonest surgical procedure which is preferred by many surgeons as it requires less expertise. The problems of postoperative pain, instability, and failed back syndrome due to postlaminectomy membrane formation had made this technique to go into disrepute. Gibson and Waddell in a Cochrane review ${ }^{12}$ has pointed out failed back syndrome due to postlaminectomy membrane formation following open laminectomy and discectomy. ${ }^{12}$ In our study, conventional technique was still done by $26.3 \%(n=20)$ which shows that surgical training on minimally invasive methods needs to improve in India.

\section{Microlumbar Discectomy}

The use of an operative microscope could obtain outcomes, comparable to laminectomy and discectomy, requiring minimal bone removal. In our survey, majority of spine surgeons $(63.8 \%, n=48)$ preferred to do MLD. Sixty-seven percent $(n=48)$ preferred to do foraminotomy to release nerve root along with routine discectomy even though there is insufficient evidence (level 1 evidence).

According to our survey, if no disc extrusion was found intraoperatively, majority $(77.8 \%, n=56)$ incised the PLL to retrieve the disc. If CSF leak was detected intraoperatively, majority preferred to widen the defect and resuture. Three percent preferred to give acetazolamide postoperatively after placing only fat graft without resuturing. At the end of laminectomy, $n=19$ (31\%) surgeons placed a Gelfoam over the dura. Thus, the surgical management techniques vary widely. This warrants the need for practice guidelines on optimal surgical management, which is lacking in India.

\section{Minimally Invasive Techniques}

A systematic review and meta-analysis by Kamper et $\mathrm{al}^{13}$ extensively studied the use of minimally invasive techniques in lumbar disc surgery. A randomized controlled trial by Arts et $\mathrm{al}^{14}$ showed good patient outcome following minimally invasive techniques. Only a few neurosurgeons (5/76) in our survey embarked on minimally 
invasive techniques. This meager number may be due to the reluctance on the part of spine surgeons to come forward and avail the good opportunities for hands on training in the field of MISS.

\section{Endoscopic Techniques}

The theoretical advantage of reduced muscle injury in the endoscopic approach is somewhat in question as creatine phosphokinase and multifidus muscle atrophy are not significantly different when compared with conventional microdiscectomy. There is only grade $\mathrm{C}$ evidence for endoscopic percutaneous discectomy in the treatment of lumbar disc herniation with radiculopathy. ${ }^{14}$ Endoscopic percutaneous discectomy is suggested for carefully selected patients to reduce early postoperative disability and reduce opioid use. ${ }^{15}$ Eleven percent $(n=8)$ of neurosurgeons in our survey were practicing endoscopic discectomy. This needs further clarification and consensus.

\section{Total Disk Arthroplasty}

This procedure has been used for lumbar discogenic pain, with and without radicular symptoms. The ProDisc prosthesis has been used for both single-level and multilevel degenerative diseases. Bertagnoli et al, ${ }^{16}$ in a 2-year study of patients older than 60 years, showed a $94 \%$ satisfaction rate with the ProDisc therapy. However, the accuracy of certain studies on ProDisc is currently being challenged. Artificial disk replacement had shown results similar to fusion in the short term, but long-term results are lacking. In our survey, only one spine surgeon practiced total disc arthroplasty which may be because of low response rate (26.6\%) in our survey. This may be pointing toward the lack of proper awareness regarding this technique in India.

\section{Percutaneous Lumbar Discectomy}

Onik et $\mathrm{Al}^{17}$ introduced automated percutaneous lumbar discectomy (APLD) in 1985. Bocchi et al ${ }^{18}$ reported the clinical results of 500 patients treated by the Onik et al method of APLD. This procedure is safer than chymopapain intradiscal injection. It allows debulking of the central disk material by placement of a needle and the use of an automated suction/cutting device. ${ }^{19}$ In our survey, percutaneous discectomy was practiced by nine neurosurgeons which is a point worth mentioning.

\section{Role of Stabilization}

The role of stabilization in lumbar disc surgery is very unclear. ${ }^{1,20}$ A Cochrane Database of Systematic Reviews ${ }^{21}$ article reviewed 33 randomized comparative studies on various fusion techniques for patients with single or multiple level degenerative disc disease. The analysis found that little or no difference was noted in pain relief between the different procedures. None of the neurosurgeons in the survey advocated spinal fusion for pain following lumbar disc diseases. This shows that Indian neurosurgeons are following the present international guidelines.

\section{Postoperative Considerations}

There is considerable variation in postoperative management also. Fifty-three percent of spine surgeons opted postoperative early mobilization. Symptomatic pain relief in patients following surgery was given a score of 8 by majority of surgeons ( $n=26,36 \%)$, measured on a continuous scale from 1 to 10. Regarding the use of drain, Mirzai et $\mathrm{al}^{22}$ found that epidural hematoma was detected in $36 \%$ of patients with a drain and in $89 \%$ of patients without a drain. Our survey showed that majority (90\%) preferred to use drain after MLD and conventional laminectomy discectomy which is in concurrence with the earlier results.

\section{Follow-up Evaluation}

In our study, 59\% preferred to follow-up patients clinically and opted for MRI only when recurrence of disc disease or infection was suspected. There is lack of consensus regarding the ideal postoperative follow-up interval following lumbar disc surgery.

\section{Analysis of Factors Playing a Role in Practice and Outcome}

The institutional nature (characterized government teaching, government nonteaching, private teaching, and private nonteaching) and location of the hospital (urban/semiurban/ rural) were found to be influencing the preferred surgical technique, trial of medical management, or postoperative care and complications. Trial of medical management for less symptomatic patients is more preferred in a nonurban region than in urban region ( 46.2 vs. $14.6 \%, p$-value $=0.013$ ). Practice of minimally invasive and endoscopic spine procedures was more seen in urban nonteaching hospital when compared with rural region though not statistically significant (92.3 vs. $10 \%, p$-value $=0.067)$. Surgical and medical management preferences of survey participants based on hospital ownership and teaching status are shown in $\mathbf{- F i g s . ~} \mathbf{7}$ and $\mathbf{8}$.

\section{Limitations}

Response rate of our survey was only $26.6 \%$ which is a poor response. Hence, it is not known how much the analysis with

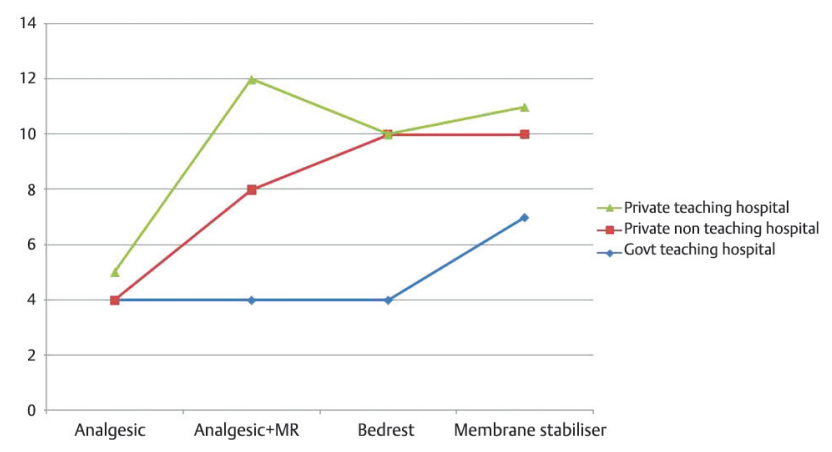

Fig. 7 Medical management preferences of survey participants based on hospital characteristics. 


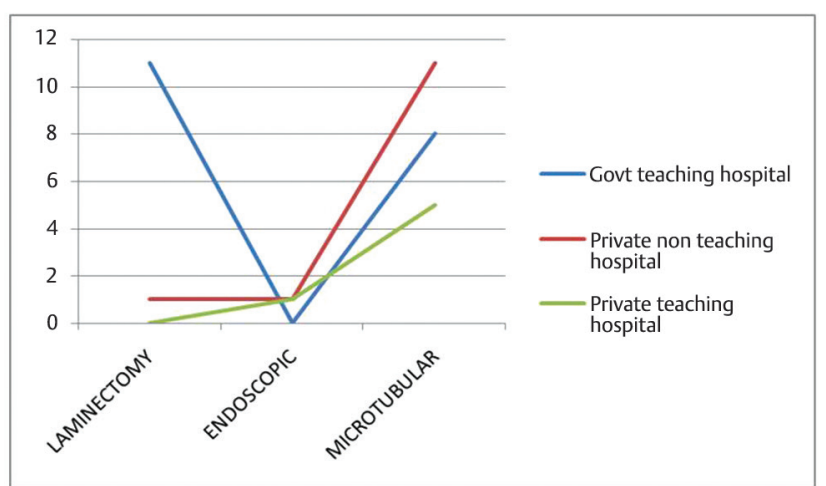

Fig. 8 Surgical management preferences of survey participants based on hospital characteristics.

the obtained data reflects the practice trends among spine surgeons nationwide. Data are collected from surgeon's reports which are dependent on personal preference and may have a recall bias. Though with these deficiencies, we hope that our survey will act as a reference for future studies and formation of Indian guidelines.

\section{Conclusion}

The preferred treatment of choice of majority is MLD, although laminectomy and discectomy were still used by many. Consensus lacks in the operative, perioperative, and postoperative management of degenerative disc disease. Present survey points toward the importance of making management guidelines for this common spinal surgical entity.

\section{Author's Contributions}

The author contributed to the concepts, design, definition of intellectual content, literature search, data acquisition, data analysis, statistical analysis, manuscript preparation, manuscript editing, manuscript review, and guarantor.

\section{Funding}

None.

\section{Conflict of Interest}

None declared.

\section{Acknowledgment}

I thank all the colleagues of Neurosurgery Department, Medical College, Kottayam for helping me in this article.

\section{References}

1 Cloward RB. The degenerated lumbar disc: treatment by vertebral body fusion. J Int Coll Surg 1954;22(4 Sect. 1) :375-386

2 Weinstein JN, Tosteson TD, Lurie JD, et al. Surgical vs nonoperative treatment for lumbar disk herniation: the Spine Patient Outcomes Research Trial (SPORT): a randomized trial. JAMA 2006;296(20):2441-2450

3 Anderson PA, McCormick PC, Angevine PD. Randomized controlled trials of the treatment of lumbar disk herniation: 1983-2007. J Am Acad Orthop Surg 2008;16(10):566-573
4 Parsons WB, Cumming JD. Mechanical traction in lumbar disc syndrome. Can Med Assoc J 1957;77(1):7-11

5 Bergmann TF, Jongeward BV. Manipulative therapy in lower back pain with leg pain and neurological deficit. J Manipulative Physiol Ther 1998;21(4):288-294

6 Kasimcan O, Kaptan H. Efficacy of gabapentin for radiculopathy caused by lumbar spinal stenosis and lumbar disk hernia. Neurol Med Chir (Tokyo) 2010;50(12):1070-1073

7 Buttermann GR. Treatment of lumbar disc herniation: epidural steroid injection compared with discectomy. A prospective, randomized study. J Bone Joint Surg Am 2004;86(4):670-679

8 Saal JA, Saal JS. Nonoperative treatment of herniated lumbar intervertebral disc with radiculopathy. An outcome study. Spine 1989;14(4):431-437

9 Atlas SJ, Deyo RA, Keller RB, et al. The Maine Lumbar Spine Study, Part II. 1-year outcomes of surgical and nonsurgical management of sciatica. Spine 1996;21(15):1777-1786

10 Peul WC, van den Hout WB, Brand R, Thomeer RT, Koes BW; Leiden-The Hague Spine Intervention Prognostic Study Group. Prolonged conservative care versus early surgery in patients with sciatica caused by lumbar disc herniation: two year results of a randomised controlled trial. BMJ 2008;336(7657): 1355-1358

11 Zhang Q, Qian J, Zhu Y. Meta-analysis on microdiscectomy and sequestrectomy for lumbar disc herniation. J Invest Surg 2015;28(4):225-229

12 Gibson JN, Waddell G. Surgical interventions for lumbar disc prolapse: updated Cochrane Review. Spine 2007;32(16): 1735-1747

13 Kamper SJ, Ostelo RW, Rubinstein SM, et al. Minimally invasive surgery for lumbar disc herniation: a systematic review and meta-analysis. Eur Spine J 2014;23(5):1021-1043

14 Arts MP, Brand R, van den Akker ME, Koes BW, Bartels RH, Peul WC; Leiden-The Hague Spine Intervention Prognostic Study Group (SIPS). Tubular diskectomy vs conventional microdiskectomy for sciatica: a randomized controlled trial. JAMA 2009;302(2):149-158

15 Jhala A, Mistry M. Endoscopic lumbar discectomy: experience of first 100 cases. Indian J Orthop 2010;44(2):184-190

16 Bertagnoli R, Yue JJ, Fenk-Mayer A, Eerulkar J, Emerson JW. Treatment of symptomatic adjacent-segment degeneration after lumbar fusion with total disc arthroplasty by using the ProDisc prosthesis: a prospective study with 2-year minimum follow up. J Neurosurg Spine 2006;4(2):91-97

17 Onik G, Helms CA, Ginsburg L, Hoaglund FT, Morris J. Percutaneous lumbar diskectomy using a new aspiration probe. AJR Am J Roentgenol 1985;144(6):1137-1140

18 Bocchi L, Ferrata P, Passarello F. The Onik method of automated percutaneous lumbar diskectomy (A.P.L.D.). Criteria of selection, technique, and evaluation of results. Ital J Orthop Traumatol 1991;17(1):5-21

19 LeBlanc FE. Sciatica-management by chemonucleolysis versus surgical discectomy. Neurosurg Rev 1986;9(1-2):103-107

20 Eie N. Comparison of the results in patients operated upon for ruptured lumbar discs with and without spinal fusion. Acta Neurochir (Wien) 1978;41(1-3):107-113

21 Yoshihara H, Yoneoka D. National trends in the surgical treatment for lumbar degenerative disc disease: United States, 2000 to 2009. Spine J 2015;15(2):265-271

22 Mirzai H, Eminoglu M, Orguc S. Are drains useful for lumbar disc surgery? A prospective, randomized clinical study. J Spinal Disord Tech 2006;19(3):171-177 